\title{
A EXPERIÊNCIA DE PROPOSIÇÃO DE ATIVIDADES ACADÊMICAS COMPLEMENTARES NOS CURSOS DE ENGENHARIA DA EESC/USP
}

\author{
Luciana Montanari - montanar@sc.usp.br \\ Departamento de Engenharia Mecânica \\ Universidade de São Paulo - Escola de Engenharia de São Carlos \\ Av. Trabalhador são-carlense, 400 \\ CEP: 13566-590 - São Carlos - SP
}

Daniel C. Amaral - amaral@ sc.usp.br

Departamento de Engenharia de Produção

Vilma A. Oliveira - voliveira@ usp.br

Departamento de Engenharia Elétrica e Computação

Resumo: A Universidade de São Paulo (USP) iniciou o reconhecimento das Atividades Acadêmicas Complementares (AACs) no ano 2000. Desde então foram instituídas ações administrativas e pedagógicas, acompanhando as resoluções de âmbito nacional sobre o tema. No ano de 2019 a USP unificou os parâmetros de implantação das AACs em paralelo à aprovação das diretrizes curriculares nacionais (DCNs) para os cursos de Engenharia pelo Ministério da Educação. As AACs foram, portanto, reconhecidas como instrumentos para a flexibilização dos currículos, inserção de vivência prática aos estudantes de graduação, promoção da autonomia e formação de competências para a atuação profissional. Este artigo relata a experiência da Comissão de Graduação (CG) da Escola de Engenharia de São Carlos (EESC) na implantação das AACs no currículo dos seus cursos de Engenharia, seguindo as diretrizes USP e DCNs. As AACs na USP foram categorizadas em atividades de ensino, pesquisa e extensão e foram definidos créditos incorporados ao histórico escolar do estudante, tão logo faça a solicitação via sistema de gestão da graduação. Cada curso identifica as diretrizes específicas no projeto pedagógico do curso $(P P C)$ e o número mínimo de créditos em AAC, seguindo uma referência comum de contagem de crédito e classificação. $O$ procedimento administrativo é o mesmo para todos os cursos. As AACs na EESC aprovadas perfazem entre 120 e 360 horas de carga horária obrigatória, com a sua implantação prevista a partir de 2021 para os novos ingressantes.

Palavras-chave: Implantação das novas DCNs. Registro de atividades acadêmicas complementares. Atribuição de carga horária. Flexibilização curricular.

\section{INTRODUÇÃ̃O}

Atividades Acadêmicas Complementares (AACs) são atividades de natureza acadêmica, científica, artística e cultural que buscam a integração entre a graduação, a pesquisa e a extensão 
para além das disciplinas obrigatórias ou optativas do currículo e são realizadas pelos estudantes ao longo do curso de graduação.

O reconhecimento das AACs pode contribuir para flexibilizar a formação profissional, científica, social e cultural do estudante, de acordo com o seu interesse e afinidades e possibilitar a participação dos discentes na construção de seu próprio currículo, incentivando formas diversificadas de aprendizagem e interação com outras áreas do conhecimento.

A USP iniciou o trabalho de reconhecimento de AACs no ano 2000, com a criação de disciplinas voltadas para o extensionismo, através da resolução Comissão de Graduação da USP (CoG) e Comissão de Cultura e Extensão (CoCEx) de n. ${ }^{\circ} 4738$ (USP, 2000). Em 2007, a Resolução CES/CNE/MEC n. ${ }^{\circ} 2$ de 18 de junho veio corroborar a ideia e a importância da inclusão de atividades de extensão nos projetos de cursos de graduação (BRASIL, 2007).

A USP permite, desde 2015, em seu sistema de graduação, o registro de horas dedicadas às essas atividades, que passaram a constar no histórico escolar, sem impacto na média ponderada do estudante (SALA DE IMPRENSA USP, 2015).

Durante os anos de 2017 e 2018 houve amplo debate sobre o tema, envolvendo as três próreitorias (Graduação, Cultura e Extensão e Pesquisa), e resultou na Resolução CoG, CoCEx e CoPq n. ${ }^{\circ}$ 7788, de 26 de agosto, publicada em 2019, que unificou e estabeleceu novas normas e disciplinas para integralização de créditos das AACs nos currículos dos cursos de graduação da USP (USP, 2019). Elas estão em consonância com a lei n. ${ }^{\circ} 16.279$, de 08 de julho de 2016, art. $2^{\circ}$, incisos V e VII do Plano Estadual de Educação de São Paulo de 2016, que havia estabelecido, entre outras diretrizes, a da formação do estudante para o trabalho e para a cidadania e a da promoção humanística, científica, cultural e tecnológica do Estado e do País (SÃO PAULO, 2016).

Também em 2019, houve a aprovação da Resolução CES/CNE/MEC n. ${ }^{\circ}$ 2, de 24 de abril de 2019, que instituiu as novas Diretrizes Curriculares Nacionais para os Cursos de Graduação em Engenharia (DCNs), que recomendam a inclusão das AACS nos currículos dos cursos de Engenharia de forma alinhada ao perfil do egresso e às competências estabelecidas (BRASIL, 2019).

Neste trabalho é apresentada a experiência de uma das unidades da USP, a Escola de Engenharia de São Carlos (EESC), na introdução das AACs no currículo de seus 10 cursos de Engenharia: Aeronáutica, Ambiental, Civil, Computação, Elétrica/Eletrônica, Automação e Energia, Materiais e Manufatura, Mecânica, Mecatrônica e Produção.

O artigo está organizado como segue. Na Seção 2 são apresentadas a motivação e a metodologia usada para a implantação da Resolução n. ${ }^{\circ} 7788$ da USP nos cursos da EESC, incluindo a inclusão das AACs na organização curricular dos seus cursos, definindo o tipo de atividade e a atribuição de créditos. Na Seção 3 são descritos os procedimentos para a implantação e o registro de AACs. Finalmente, na Seção 4, encontram-se as considerações finais.

\section{MOTIVAÇÃO E METODOLOGIA}

A EESC possui uma tradição de grupos de extensão e equipes de competição de engenharia. Por exemplo, a equipe EESC Baja SAE participa desde a primeira edição da competição SAE Brasil de Mini Baja que ocorreu em 1995 (EESC BAJA SAE, 2020). Já a EESC Jr. foi fundada em 1992 (EESC Jr., 2020) e, desde então, diversos estudantes participam das atividades, realizando projetos e serviços que contribuem para o desenvolvimento acadêmico e profissional, capacitando-os para o mercado de trabalho. Atualmente, há 40 grupos e atividades de cultura e extensão cadastrados no site da EESC (GCEx, 2020). O número de 
estudantes vinculados aos grupos e às atividades mudam a cada ano em função dos seus interesses. A dificuldade em reconhecer as atividades dos grupos de extensão e as equipes de competição é um problema recorrente enfrentado por gestores de graduação e a comunidade discente. Em 2000, surgiram as primeiras disciplinas de extensão, após aprovação desta modalidade pela Pró-Reitoria de Graduação da USP. E em 2015, as atividades passaram a ser contabilizadas no sistema de gestão da graduação.

A direção da USP ampliou o conceito de disciplinas de extensão em 2019 para contabilizar a carga horária de atividades de extensão e, recentemente, a USP considera, além da extensão, os dois outros pilares da atuação universitária: pesquisa e ensino através da resolução CoG, CoCEx e Comissão de Pesquisa (CoPq), n. 7788 (USP, 2019). Assim, as atividades complementares dos cursos podem ser classificadas em:
$\checkmark$ Acadêmicas Complementares de Graduação (AACG);
$\checkmark$ Acadêmicas Complementares de Cultura e Extensão Universitária (AACCE);
$\checkmark$ Atividades Acadêmicas Complementares de Pesquisa (AACPq).

A inclusão da pesquisa está alinhada à política institucional da USP, uma universidade que se compromete, se destaca e tem como missão a melhoria da sociedade não apenas pela educação, mas também por meio da pesquisa científica e a sua aplicação tecnológica. Por isso, são consideradas em mesmo grau de importância as atividades oriundas das três formas de atuação universitária: ensino, pesquisa e extensão. Está também alinhada às novas DCNs que destacam a importância da integração entre a graduação e a pós-graduação e o aperfeiçoamento de suas relações. Essas relações podem ser com a iniciação científica, a participação em grupos de pesquisa, disciplinas que se articulam ao programa de pós-graduação, entre outras. A integração graduação e pós-graduação contribui para a formação de engenheiros com formação científica mínima e o oferecimento de "trilhas" para a formação de engenheiros capazes de atuar em pesquisa.

Em um ensaio reflexivo sobre a integração entre o trabalho de pesquisa e o ensino nas universidades, Loiola (2018) identifica dinâmicas sociais e mudanças nos contextos das universidades públicas que, segundo o autor, geraram uma "divisão social e intelectual das funções de pesquisa e do ensino no Brasil. A pesquisa foi assumida por um grupo de docentes, "especialistas", e o ensino passou a ser uma responsabilidade de um corpo docente distanciado de produção de saberes. $\mathrm{O}$ direcionamento para incluir as atividades de pesquisa nas atividades acadêmicas complementares, tanto da USP quanto das novas DCNs, é uma resposta para o distanciamento apontado e sinaliza aos docentes e discentes que os três componentes, ensino, pesquisa e extensão, são igualmente importantes.

A visão de integração foi especialmente reforçada na EESC durante o processo de estabelecimento de suas diretrizes curriculares, realizado entre 2013 e 2014, pela Diretoria e Congregação. As diretrizes para estrutura curricular dos cursos da EESC foram aprovadas na $589^{a}$ reunião da Congregação, em sessão de 5/12/2014. E indicam, entre tantas ações, a integração entre o ensino de graduação e a pesquisa para todos os cursos da EESC (EESC, 2014; PROENÇA, 2016).

O processo de introdução das AACs na EESC, cuja cronologia é esquematizada na Figura 1, teve como resultado um conjunto de definições e processos administrativos alinhados com a Resolução CES/CNE/MEC n. ${ }^{\circ}$ 2, de 24 de abril de 2019, que estabelece as diretrizes para os cursos de graduação em engenharia (BRASIL, 2019). 
Figura 1 - Cronologia das resoluções e processo de implantação das AACs na EESC.

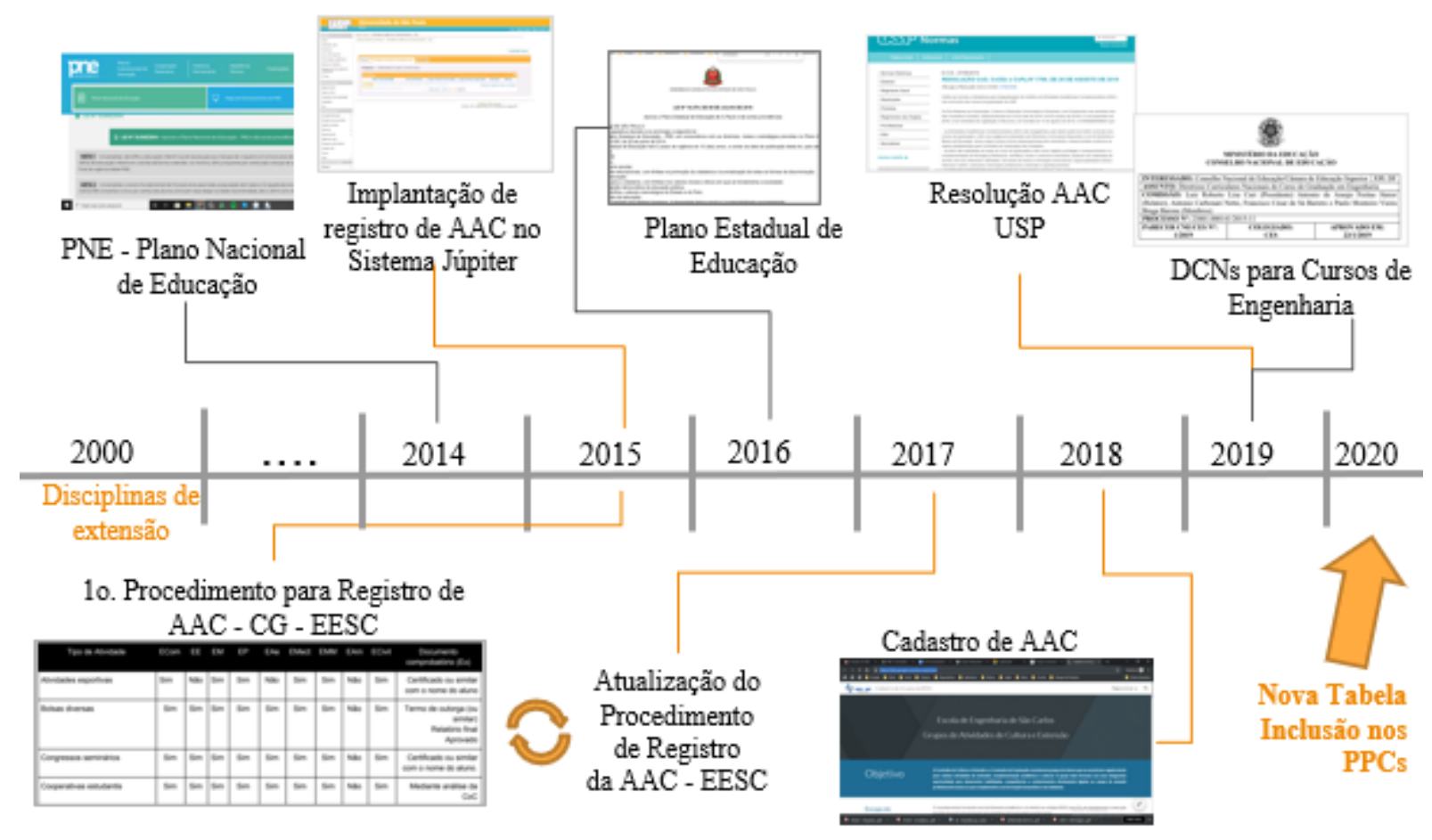

Fonte: Próprio autor

\subsection{Incluindo as AACs na organização curricular dos cursos}

Sendo as AACs parte obrigatória das atividades curriculares dos cursos, o estudante deverá cumprir um número mínimo de horas dessas AACs, que podem ser desenvolvidas do início ao final do curso de graduação. O estudante estrutura o seu plano de ação e decide em quais AACs deseja se envolver, de acordo com as suas necessidades vocacionais, curiosidade intelectual, guiados pelo perfil das competências e diretrizes específicas estabelecidas pelo PPC dos cursos. Ele pode desenvolver essas atividades dentro ou fora dos muros da Universidade. As AACs devem estar de acordo com as competências estabelecidas no perfil de egresso nos PPCs, de forma a garantir o alinhamento das experiências com o desenvolvimento das competências do egresso.

A Comissão de Graduação da Escola de Engenharia de São Carlos (CG-EESC) delegou, para cada curso, a definição do número mínimo de carga horária obrigatória, mas estabeleceu um padrão de mínimo e máximo, uma faixa entre 120 e 360 horas, convertidas em créditostrabalho.

Diferente da Resolução CES/CNE/MEC n. ${ }^{\circ} 2$ de 18 de junho de 2007, que estabelece que as atividades escolhidas não devem ultrapassar $20 \%$ da carga horária total do curso, a Resolução CoG, CoCEx e CoPq n. ${ }^{\circ} 7788$, de 26 de agosto de 2019, preconiza que as AACs devem perfazer até 10\% da carga horária total do curso (BRASIL, 2007; USP, 2019). Como a carga horária mínima de um curso de Engenharia deve ser de 3600 horas, de acordo com a Resolução CNE/CES n ${ }^{\circ}$ 2, de 18 de junho de 2007, foi estabelecido o valor máximo de 360 horas para os cursos de Engenharia da EESC (BRASIL, 2007). O valor de créditos mínimos em AAC, estabelecido em cada PPC, será verificado para fins de obtenção do diploma. 
Também como forma de padronização, a CG-EESC aprovou uma lista de AACs permitidas nas 3 categorias, ensino, pesquisa e extensão, identificando os documentos a serem exigidos para fins de verificação e aprovação. Assim, todos os estudantes de engenharia da unidade possuem uma referência comum a ser seguida, tanto no que diz respeito ao tipo de atividade, como no número de créditos acumulados e também quanto aos procedimentos administrativos. A diferença entre os cursos será apenas o número mínimo que precisa ser concretizado para fins de recebimento do diploma.

\subsection{Atribuição de créditos}

A definição de quais atividades realizar é uma decisão individual do estudante, conforme plano vocacional e de carreira. O controle do tempo total de dedicação é realizado pelo estudante, procedimento que confere protagonismo, provocando mudanças em sua atitude durante a sua formação.

Seguindo a regulamentação da USP (USP, 2019), a EESC definiu uma lista nas categorias de atividades como AACG, AACCE e AACPq. E, como forma de garantir flexibilidade na escolha do estudante, a CG-EESC orientou o não estabelecimento de limite de AACs por categoria para cômputo dos créditos-trabalho obrigatórios.

A atribuição de créditos para cada atividade foi estabelecida de forma a garantir uma experiência diversa ao estudante, aproveitando os tipos de AACs. Para atingir esse objetivo, o número de créditos para as diferentes atividades foi definido entre 1 e 3 . O número máximo de créditos foi atribuído às atividades com maior aderência ao projeto pedagógico do curso e exigência de maior dedicação dos estudantes.

\section{DEFINIÇÃO DE ATIVIDADES E NÚMERO MÁXIMO DE CRÉDITOS}

A definição das AACs nas categorias estabelecidas considerou as oportunidades já oferecidas para o estudante do Campus USP São Carlos, com destaque para as atividades relacionadas às equipes de competição e os grupos de extensão regulamentadas pela EESC. As Tabelas 1a, 1b e 1c apresentam a relação final para as categorias AACG, AACCE e AACPq.

Tabela 1a - Atividades para a categoria AACG com número máximo de créditos (Cred.) e comprovante.

\begin{tabular}{c|c|c}
\hline Descrição da atividade & Cred. & Comprovante \\
\hline $\begin{array}{c}\text { Monitoria em cursos de graduação } \\
\text { Recebimento de bolsas em projetos de modalidade } \\
\text { de ensino }\end{array}$ & 2 & $\begin{array}{c}\text { Lista da secretaria do } \\
\text { Departamento }\end{array}$ \\
$\begin{array}{c}\text { Premiações acadêmicas na graduação } \\
\text { Estágios acadêmicos não obrigatórios }\end{array}$ & 2 & $\begin{array}{c}\text { Termo de outorga (ou similar) e } \\
\text { relatório final aprovado } \\
\text { Indicação }\end{array}$ \\
$\begin{array}{c}\text { Participação na organização de eventos de } \\
\text { graduação (semanas de engenharia, seminários e e } \\
\text { conferências científicas) }\end{array}$ & 2 & $\begin{array}{c}\text { Certificado ou similar com o nome } \\
\text { horas e menção da função } \\
\text { do estudante }\end{array}$ \\
$\begin{array}{c}\text { Participação em programas de atividades } \\
\text { extramuros relacionadas à prática profissional do } \\
\text { curso de graduação no qual está matriculado }\end{array}$ & 2 & $\begin{array}{c}\text { Declaração e relatório assinados } \\
\text { pelo supervisor ou equivalente } \\
\text { responsável pela atividade }\end{array}$ \\
$\begin{array}{c}\text { Participação em atividades acadêmicas na Agência } \\
\text { USP de Inovação }\end{array}$ & 1 & $\begin{array}{c}\text { Certificado ou similar com o nome } \\
\text { do estudante }\end{array}$
\end{tabular}


Participação em atividades de empreendedorismo e mercado financeiro

Participação em visitas acadêmicas, culturais e de extensão monitoradas na Unidade

Organização/apoio a visitas abertas à comunidade

Participação na Comissão da Semana de Recepção aos Calouros

Fonte: EESC (2020)

Declaração do responsável e relatório resumido dos resultados

Lista de participantes

Declaração do responsável pela atividade

Certificado ou similar com o nome do estudante

Tabela 1b - Atividades para a categoria AACCE com número máximo de créditos (Cred.) e comprovante.

\begin{tabular}{|c|c|c|}
\hline Descrição da atividade & Cred. & Comprovante \\
\hline Participação em edição do Projeto Rondon & 2 & Declaração do responsável \\
\hline $\begin{array}{l}\text { Representação discente em colegiados e entidades } \\
\text { estudantis (cargos Centro Acadêmico e diretoria } \\
\text { de secretarias acadêmicas) }\end{array}$ & 2 & Resultado da eleição \\
\hline $\begin{array}{l}\text { Participação em cursos de extensão universitária, } \\
\text { cursando ou apoiando o oferecimento }\end{array}$ & 1 & $\begin{array}{l}\text { Certificado de apoio ou conclusão } \\
\text { do curso }\end{array}$ \\
\hline Participação em empresas juniores & 2 & $\begin{array}{c}\text { Declaração do presidente da } \\
\text { empresa júnior contendo lista dos } \\
\text { integrantes e horas dedicadas no } \\
\text { semestre }\end{array}$ \\
\hline $\begin{array}{c}\text { Participação em grupos e organizações que } \\
\text { promovam ações sociais }\end{array}$ & 2 & $\begin{array}{c}\text { Declaração do responsável pelo } \\
\text { grupo }\end{array}$ \\
\hline $\begin{array}{c}\text { Participação em programa de extensão de serviços } \\
\text { à comunidade }\end{array}$ & 2 & $\begin{array}{l}\text { Declaração do responsável pelo } \\
\text { grupo }\end{array}$ \\
\hline $\begin{array}{c}\text { Participação em competição estudantil inclui } \\
\text { competição esportiva }\end{array}$ & 2 & $\begin{array}{l}\begin{array}{c}\text { Declaração do responsável pelo } \\
\text { grupo }\end{array} \\
\text {. }\end{array}$ \\
\hline Organização de competições esportivas & 1 & $\begin{array}{l}\text { Certificado ou declaração do } \\
\text { responsável pelo grupo }\end{array}$ \\
\hline $\begin{array}{c}\text { Ministrar ou participar de treinamentos técnicos } \\
\text { desde que fora de estágio }\end{array}$ & 1 & $\begin{array}{l}\text { Certificado ou declaração do } \\
\text { responsável pelo treinamento }\end{array}$ \\
\hline $\begin{array}{l}\text { Recebimento de bolsas em projetos de modalidade } \\
\text { cultura e extensão }\end{array}$ & 2 & $\begin{array}{l}\text { Declaração do coordenador do } \\
\text { projeto }\end{array}$ \\
\hline Recebimento de premiações sociais/comunitárias & 1 & Certificado \\
\hline Participação em semanas acadêmicas & 1 & $\begin{array}{l}\text { Declaração do docente responsável } \\
\text { pela organização da Semana }\end{array}$ \\
\hline $\begin{array}{c}\text { Participação em atividades culturais em museus, } \\
\text { institutos especializados e centros culturais, e } \\
\text { curadoria }\end{array}$ & 1 & Declaração \\
\hline
\end{tabular}


Tabela 1c - Atividades para a categoria AACPq com número máximo de créditos (Cred.) e comprovante.

\begin{tabular}{|c|c|c|}
\hline Descrição da atividade & Cred. & Comprovante \\
\hline Realização de iniciação científica & 3 & $\begin{array}{l}\text { Termo de outorga (ou similar para } \\
\text { o Sistema USP) e relatório final }\end{array}$ \\
\hline $\begin{array}{l}\text { Recebimento de bolsas em projetos de modalidade } \\
\text { de pesquisa }\end{array}$ & 2 & $\begin{array}{c}\text { Declaração do coordenador do } \\
\text { projeto }\end{array}$ \\
\hline Recebimento de premiações científicas & 2 & Resultado divulgado \\
\hline $\begin{array}{c}\text { Participação em congressos, seminários e } \\
\text { conferências científicas com apresentação de } \\
\text { trabalhos }\end{array}$ & 1 & $\begin{array}{l}\text { Certificado de apresentação do } \\
\text { trabalho }\end{array}$ \\
\hline $\begin{array}{c}\text { Participação em atividades de pesquisa na } \\
\text { Agência USP de Inovação }\end{array}$ & 2 & Declaração da Agência \\
\hline $\begin{array}{c}\text { Participação na autoria de artigos científicos e nos } \\
\text { registros de patentes }\end{array}$ & 2 & Publicação ou aceite \\
\hline
\end{tabular}

Fonte: EESC (2020)

A lista dos tipos de atividades, incluindo os números correspondentes de créditos, está disponível na intranet da EESC, seção do Serviço de Graduação bem como o procedimento para a solicitação dos créditos no Sistema Web da Graduação. A Figura 2 apresenta a tela de entrada da intranet, que pode ser acessada em https://eesc.usp.br/intranet/.

Figura 2 - Tela de acesso às instruções para solicitação de cadastro de AACs

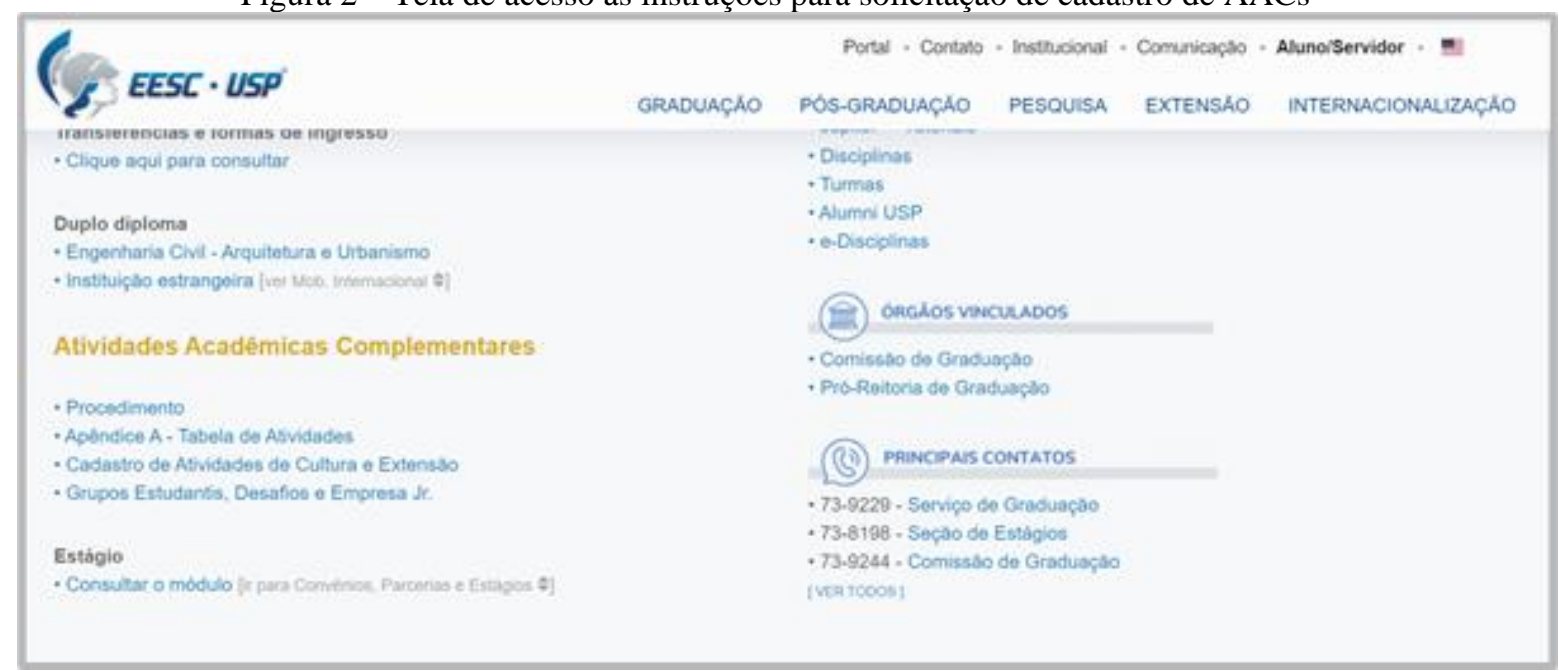

Fonte: Página Web Graduação USP

\subsection{Instruções para o registro de AACs}

A USP implementou um procedimento geral que detalha o processo de registro da AAC a ser seguido no sistema Web da Graduação, desde o pedido do estudante até a sua aprovação, se estiver de acordo com a deliberação da CG-EESC, em termos do tipo de atividade e carga horária máxima. Os detalhes contidos no procedimento foram delegados para as Unidades e, no caso da EESC, para que as Comissões Organizadoras de Curso (CoCs) desenvolvam padrões que orientem a aprovação dos pedidos. 
A CG-EESC estabeleceu um procedimento complementar e específico da unidade que orienta os docentes gestores de cursos e funcionários envolvidos no processo administrativo.

\subsection{Etapas do procedimento para o registro de AACs}

$\mathrm{O}$ estudante deve cadastrar o requerimento no sistema Web da Graduação, anexando o documento comprobatório, conforme a Tabela de AACs aprovada pela CG-EESC (https://eesc.usp.br/intranet/). O procedimento envolve os seguintes passos:

1. O estudante cadastra o pedido de requerimento (Figura 3);

2. O Serviço de Graduação avalia o cadastro pedido (se está de acordo com a Tabela 1, e se o documento condiz com o assunto) e o documento comprobatório. Se tudo em ordem, encaminha ao Coordenador do Curso. Caso contrário pode indeferir o pedido ou devolver ao estudante para correção;

3. O Coordenador do Curso analisa o pedido deferindo-o ou não e aprovando o número de horas estabelecido para cada AAC;

4. A carga horária da AAC passará a constar no histórico escolar (as horas obrigatórias serão computadas e as demais serão listadas).

Figura 3 - Tela do sistema Web da Graduação com a descrição das atividades.

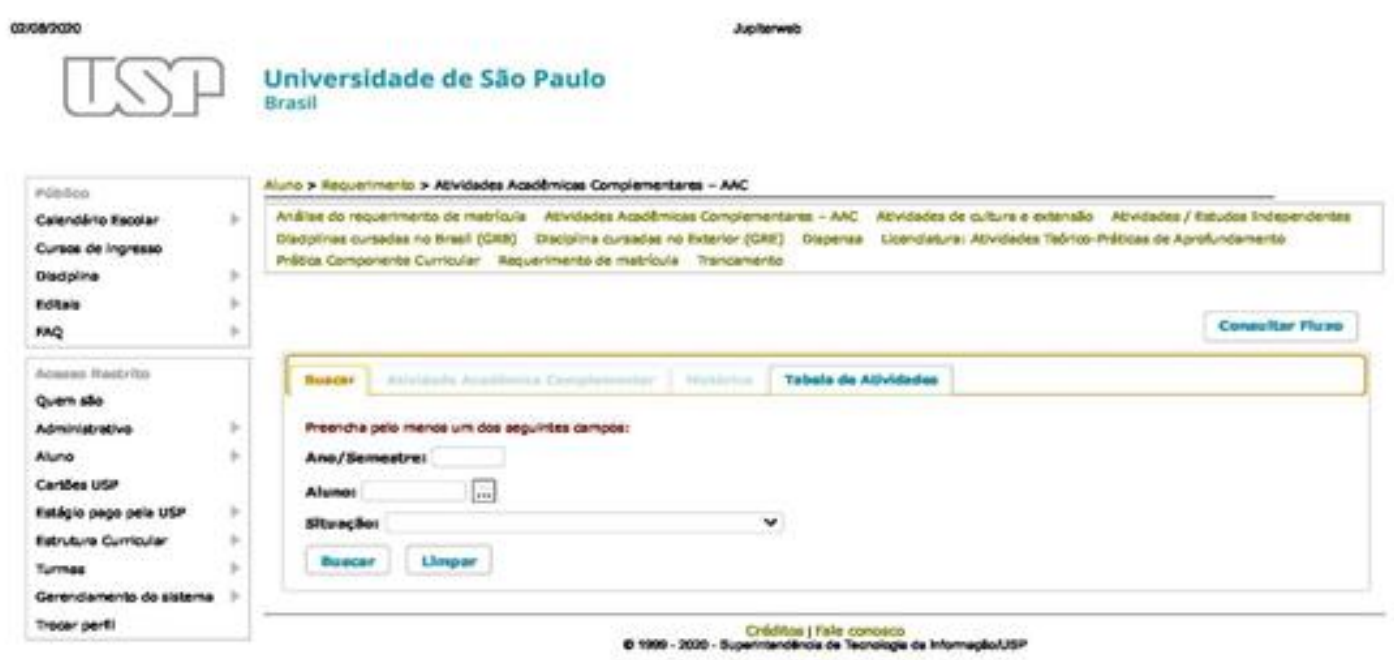

Fonte: Página Web Graduação USP

\section{CONSIDERAÇÕES FINAIS}

Em época de profundas transformações é importante proporcionar condições e motivações para que os estudantes sejam protagonistas do seu próprio aprendizado e concluam os seus cursos mais bem preparados. A implantação das AACs na organização curricular caminha no sentido de contribuir para a flexibilização curricular, articulando o desenvolvimento de competências do campo de formação com ações junto à comunidade, de caráter técnico, científico, cultural e social.

As resoluções existentes, por si só, não garantem a implantação das AACs aos currículos. É preciso que se tenha uma estratégia que subsidie a implantação e a estruturação de recursos normativos e de apoio. A CG-EESC criou o seu próprio mecanismo para incorporar as AACs aos PPCs dos seus cursos e apresentou como será viabilizado aos seus estudantes, de maneira 
transparente e objetiva. Trata-se também de um processo de amadurecimento, destacando a importância de ações consistentes e que se complementam. A proposta apresentada unificou as atividades e respectivo número de créditos máximos de forma a estimular o estudante a ter experiências diversas aproveitando as oportunidades oferecidas nas categorias de ensino, pesquisa e extensão.

\section{Agradecimentos}

Os autores agradecem os coordenadores de curso e os membros da Comissão de Graduação da EESC.

\section{REFERÊNCIAS}

BRASIL (Ministério da Educação). Resolução no 2, de 18 de junho de 2007. Dispõe sobre carga horária mínima e procedimentos relativos à integralização e duração dos cursos de graduação, bacharelados, na modalidade presencial. Disponível em <http://www.cfess.org.br/arquivos/legislacao_resolucao02.pdf>. Acesso em: 9 de ago. de 2020 .

BRASIL (Ministério da Educação). Resolução CES/CNE/MEC n. ${ }^{\circ}$ 2, de 24 de abril de 2019. Dispõe sobre diretrizes curriculares nacionais do curso de graduação em engenharia.

Disponível em: <https://www.in.gov.br/web/dou/-/resoluÇÃo-no -2-de-24-de-abril-de-201985344528>. Acesso em: 9 de ago. de 2020.

EESC BAJA SAE. Disponível em: <http://baja.eesc.usp.br/competicoes.html>. Acesso em: 18/9/2020.

EESC Jr. Disponível em: <https://eescjr.com.br/sobre/>. Acesso em 18 de set. de 2020.

ESCOLA DE ENGENHARIA DE SÃO CARLOS (EESC). Diretrizes para a estrutura curricular dos cursos da EESC. São Carlos: USP, 2014. Disponível em:

$<$ https://eesc.usp.br/comunicacao/wp-content/uploads/2020/08/22_Diretrizes.pdf >. Acesso em: 9 de ago. de 2020.

GRUPOS DE CULTURA E EXTENSÃO DA EESC (GCEx). Disponível em: $<$ https://sites.google.com/eesc.usp.br/aac/página-inicial/lista-de-atividades-extracurricularesda-eesc >. Acesso em: 18 de set. de 2020.

LOIOLA, Francisco Antônio. Articulação Entre Pesquisa e Ensino em Sala de Aula um Desafio para o Saber e a Prática Docente Universitária. Revista Educação em Debate, 2018.

PROENÇA, S. P. B. Construção de um currículo interdisciplinar de graduação em engenharia. In: PHILIP, A.; FERNANDES, V.; PACHECO, R. C.S. (org.). Ensino, Pesquisa e Inovação. 1ed. São Paulo: Manole, 2016, v. 1, p. 614-667.

SALA DE IMPRENSA - USP. Atividade complementar pode ser registrada no histórico escolar. Disponível em: <http://www.usp.br/imprensa/?p=48721>. Acesso em 9 de ago. de 2020 . 
SÃO PAULO (Estado). Lei n. ${ }^{\circ} 16.279$, de 08 de julho de 2016, art. $2^{\circ}$, incisos V e VII. Dispõe sobre o plano estadual de educação de São Paulo, 2016. Disponível em:

<https://www.al.sp.gov.br/repositorio/legislacao/lei/2016/lei-16279-08.07.2016.html>.

Acesso em: 9 de ago. de 2020.

UNIVERSIDADE DE SÃO PAULO. Resolução CoG, CoCEx e n. ${ }^{\circ}$ 4738, de 22 de fevereiro de 2000. Dispõe sobre disciplina optativa "Atividades de Cultura e Extensão", nos currículos dos cursos de graduação da USP. Disponível em:

$<$ http://www.leginf.usp.br/?resolucao=resolucao-cog-e-cocex-no-4738-de-22-de-fevereiro-de2000>. Acesso em: 9 de ago. de 2020.

UNIVERSIDADE DE SÃO PAULO. Resolução CoG, CoCEx e CoPq nº 7788, de 26 de agosto de 2019. Dispõe sobre a integralização de créditos de Atividades Acadêmicas Complementares (AAC), nos currículos dos cursos de graduação da USP, através de revogação da resolução CoG e CoCEx n ${ }^{\circ} 4738$, de 22 de fevereiro de 2000. Disponível em: $<$ http://www.leginf.usp.br/?resolucao=resolucao-cog-cocex-e-copq-no-7788-de-26-de-agostode-2019>. Acesso em: 9 de ago. de 2020.

\title{
THE EXPERIENCE OF PROPOSING COMPLEMENTARY ACADEMIC ACTIVITIES IN EESC / USP ENGINEERING COURSES
}

\begin{abstract}
The valorization of Complementary Academic Activities (AACs) at USP began in 2000. Since then, resolutions have been instituted, both at USP and at the National level. In 2019, a USP resolution culminated in recommending the implementation of AACs, as well as the new curricular guidelines for Engineering courses, from the Federal government. This article reports the experience of the Undergraduate Committee of the São Carlos School of Engineering in implementing the AACs in the curriculum of its Engineering courses, following the guidelines of USP and DCNs. The AACs at USP were categorized into teaching, research and extension activities and credits were defined to be incorporated into the student's academic record. Each course identifies specific guidelines in its teaching and learning project and the minimum number of AAC credits, following a common credit score and classification reference. The administrative procedure is the same for all courses. The CAA approved by the EESC defined between 120 and 360 hours for the mandatory workload and it is expected to be implemented for the new coming students in 2021.
\end{abstract}

Keywords: Implementing the new DCNs. Accounting for complementary academic activities. Credits assignments. Curricular flexibility. 